\title{
A mini review on aflatoxin exposure in Malaysia: past, present, and future
}

\author{
Sabran Mohd-Redzwan ${ }^{1}$, Rosita Jamaluddin ${ }^{1}{ }^{*}$, Mohd Sokhini Abd.-Mutalib ${ }^{1}$ and Zuraini Ahmad ${ }^{2}$ \\ 1 Department of Nutrition and Dietetics, Faculty of Medicine and Health Sciences, Universiti Putra Malaysia, Serdang, Malaysia \\ ${ }^{2}$ Department of Biomedical Sciences, Faculty of Medicine and Health Sciences, Universiti Putra Malaysia, Serdang, Malaysia
}

\section{Edited by:}

Mehdi Razzaghi-Abyaneh, Pasteur

Institute of Iran, Iran

\section{Reviewed by:}

Eva-Guadalupe Lizárraga-Paulín, Universidad Nacional Autónoma de México, Mexico

Perng-Kuang Chang, Southern

Regional Research Center, USA

\section{*Correspondence:}

Rosita Jamaluddin, Department of Nutrition and Dietetics, Faculty of Medicine and Health Sciences, Universiti Putra Malaysia, 43400 Serdang, Selangor, Malaysia e-mail: rosita@medic.upm.edu.my
This mini review article described the exposure of aflatoxin in Malaysia, including its presence in the foodstuffs and the detection of aflatoxin biomarkers in human biological samples. Historically, the exposure of aflatoxin in Malaysia can be dated in 1960s where an outbreak of disease in pig farms caused severe liver damage to the animals. Later, an aflatoxicosis case in Perak in 1988 was reported and caused death to 13 children, as up to $3 \mathrm{mg}$ of aflatoxin was present in a single serving of contaminated noodles. Since then, extensive research on aflatoxin has been conducted in Malaysia. The food commodities such as peanuts, cereals, spices, and their products are the main commodities commonly found to be contaminated with aflatoxin. Surprisingly, some of the contaminated foods had levels greater than the permissible limit adopted by the Malaysian Food Regulation 1985. Besides, exposure assessment through the measurement of aflatoxin biomarkers in human biological samples is still in its infancy stage. Nevertheless, some studies had reported the presence of these biomarkers. In fact, it is postulated that Malaysians are moderately exposed to aflatoxin compared to those high risk populations, where aflatoxin contamination in the diets is prevalent. Since the ingestion of aflatoxin could be the integral to the development of liver cancer, the incidence of cancer attributable by dietary aflatoxin exposure in Malaysia has also been reported and published in the literatures. Regardless of these findings, the more important task is to monitor and control humans from being exposed to aflatoxin. The enforcement of law is insufficient to minimize human exposure to aflatoxin. Preventive strategies include agricultural, dietary, and clinical measures should be implemented. With the current research on aflatoxin in Malaysia, a global networking for research collaboration is needed to expand the knowledge and disseminate the information to the global scientific community.

Keywords: aflatoxin, aflatoxin $B_{1}$, aflatoxin exposure, Malaysia, Southeast Asia

\section{INTRODUCTION}

There are many toxic compounds produced by fungi and one of them is mycotoxin. The occurrence of mycotoxin in the food commodities can be dated as early as in the tenth century. The infection of fungi in the diets caused the outbreak of disease known as St. Anthony's or Holy Fire in many European countries (Paterson and Lima, 2010). Paterson and Lima (2010) reported the outbreak was intensified with the contamination of rye by ergot alkaloid, produced by Claviceps purpurea. Since then, many cases have been reported and the discovery of "Turkey X" disease caused by aflatoxin, in 1950s and early 1960s had opened new prospectus on the scientific research on the etiology of mycotoxicosis and preventive strategies in foods, animals, and humans (Kensler et al., 2011). Kensler et al. (2011) described the epidemic disease as the major cause of death of numerous poultry animals including ducklings and chicks due to the consumption of diet containing contaminated peanuts. Further investigations at that time revealed the toxicity was associated with Aspergillus flavus, a pathogenic fungus and extracts from the culture of the fungus isolated from the meal were found to have the capability to induce the "Turkey X" syndromes (Kensler et al., 2011). Due to this, most of the reported cases on mycotoxicosis focused on specific species of fungi that are found in many contaminated foods and feeds. Indeed, four major species of fungi have been discovered belonging to the species of Aspergillus, Fusarium, Penicillium, and Claviceps that produced some major mycotoxins such as aflatoxin, ochratoxin A, fumonisim, and zearalenone (Paterson and Lima, 2010). Of these four mycotoxins, research on aflatoxin has been extensively conducted as aflatoxin represents the global main threat due to its toxicity (Paterson and Lima, 2010; Kensler et al., 2011)

Aflatoxin is produced by A. flavus, A. paraciticus, and A. nomius and ubiquitously found in foodstuffs (Reddy et al., 2011). Since aflatoxins are visible under ultraviolet (UV) light, the first attempt to detect aflatoxin is mainly based on this criteria (Groopman et al., 2005). Later the isolation of purified aflatoxin metabolites with identical physical and chemical properties formed the core to the scientific research on aflatoxin (Kensler et al., 2011). These findings have stimulated numerous research efforts, which transcend to the present, to assess possible hazards of aflatoxin contamination in the human food sources and finally to reduce the exposure through various preventive strategies. In one of many instances, the development of analytical methods to detect and 
quantify aflatoxin in foods and feeds is significance (Kensler et al., 2011) as more studies are able to be conducted to determine the association of aflatoxin ingestion with diseases in human population, especially with the incidence of hepatocellular carcinoma (HCC). Moreover, as the science is moving forward in parallel to the advancement of technology, the development of method for structural characterization, and synthesis of the major aflatoxins has led to better understanding of the mechanistic studies of their toxicology and metabolism (Groopman et al., 2005; Paterson and Lima, 2010; Kensler et al., 2011). For instance, the isolation of aflatoxin biomarkers in human biological samples such as serum $\mathrm{AFB}_{1}$-DNA adduct, $\mathrm{AFB}_{1}$-lysine adduct, and other metabolites of $\mathrm{AFB}_{1}$ in urine and feces (Wang et al., 1999; Mykkänen et al., 2005; Polychronaki et al., 2008) can give a better indication on the extent of human exposure to aflatoxin. These data are essential for the risk assessment as more concrete evidence can be used to evaluate human exposure to aflatoxin in a population.

\section{PAST-HISTORY OF AFLATOXIN IN MALAYSIA}

Malaysia is one of the Southeast Asia countries and geographically located in the equatorial area. Due to that, Malaysia experiences tropical climate with high temperature around $28-31{ }^{\circ} \mathrm{C}$ (Abdullah et al., 1998). On average, the relative humidity ranged from 70 to $80 \%$ during wet season and 50-60\% during the dry season (Sulaiman et al., 2007). Furthermore, commodities stored under these conditions are easily deteriorated and susceptible to fungal infections (Abdullah et al., 1998; Sulaiman et al., 2007). With these conditions, the most prominent contamination is the infection of foods by mycotoxin-producing fungi. Aflatoxin, one of the mycotoxin is produced by Aspergillus species of fungi and this toxin has been classified by the International Agency for Research on Cancer (IARC) as Group 1 carcinogen and is linked to the development of liver cancer (International Agency for Research on Cancer [IARC], 1993).

In Malaysia, the first indicator of problem associated with aflatoxin occurred around 1960s due to the outbreak of disease in two pig farms in Malacca (Hamid, 1997). Lim and Yeap (1966) reported the presence of aflatoxin in the feed ingredients, supported the evidences of severe liver damage to the animals. However, an episode in Perak, Malaysia around 1988 reminded the hazard of aflatoxin to human health, as the public was shocked by the death of 13 children as a result of consuming contaminated noodles called loh shi fun. The post-mortem was performed and the cause of death was associated with acute hepatic encephalopathy (Lye et al., 1995). The culprit was aflatoxin as Lye et al. (1995) reported up to $3 \mathrm{mg}$ of aflatoxin was detected in a single serving of loh shi fun. Furthermore, the wheat flour used to make the noodles was reported to contain aflatoxin due to the poor storage and processing, which in turn promoted the growth of pathogenic Aspergillus fungi and subsequently the production of aflatoxin. Since then, extensive research on aflatoxin has been carried out and the first monitoring was performed by the Institute of Medical Research (IMR), followed by other agencies such as The Food Technology Center (FTC), MARDI, and local universities (Hamid, 1997). Up till know, various studies in Malaysia have reported the presence of aflatoxin in the foodstuffs. Moreover, the biomarkers of aflatoxin have also been reported recently in serum and urine samples, which can provide additional information for assessing aflatoxin exposure in Malaysia.

\section{PRESENT - OCCURRENCE OF AFLATOXIN IN THE FOOD COMMODITIES, HUMAN EXPOSURE AND RISK ASSESSMENT}

The contamination of foodstuffs by aflatoxin has been documented in the literatures. Peanuts, cereals, spices, and their products are the commodities most susceptible to aflatoxin contamination. These food commodities are generally used in many Malaysian delicacies either as a main ingredient or as a base material (Reddy et al., 2011). In fact, they are available almost in all retail shops in Malaysia and are inexpensive. For example, various studies have detected aflatoxin in the peanuts and peanut-based products as shown Table 1. Sulaiman et al. (2007) indicated that raw shelled peanut and its products are the good substrate for the growth of aflatoxin by A. flavus and A. paraciticus. Even though peanuts are not extensively produced in Malaysia, the occurrence of aflatoxin in this food commodity is frequently reported. Moreover, Leong et al. (2011) postulated that high level of $\mathrm{AFB}_{1}$ in nuts can result in the high potential risk of $\mathrm{AFB}_{1}$ exposure in Malaysia. In fact, Malaysians probably consume higher amount of $\mathrm{AFB}_{1}$ than Europeans and Americans but lower than those in Africa and China (Leong et al., 2011).

Cereals such as rice are one of the main agricultural products in Malaysia. The presence of aflatoxin in the rice could pose serious health issues. For example, in a study by Soleimany etal. (2012a), 33.3\% of analyzed rice from the retail market had detectable level of aflatoxin ranging from 0.19 to $3.96 \mathrm{ng} / \mathrm{g}$. Even though the levels are not considered dangerous and harmful to humans, it was an unexpected finding as rice is the main staple food consumed by majority of Malaysian. Statistically, Malaysians consume rice about $289.68 \mathrm{~g} /$ day (Ministry of Health $[\mathrm{MOH}], 2006)$. Thus it is assumed that dietary aflatoxin exposure from rice is somewhere between $55.04 \mathrm{ng} /$ day and $1.15 \mu \mathrm{g} /$ day [288.68 g/day $\times 0.19$ or $3.96 \mathrm{ng} / \mathrm{g}$ ] for an adult of $60 \mathrm{~kg}$. Given that the aflatoxin-contaminated rice is consumed on a regular basis, this small amount of aflatoxin at the end will be accumulated in the body and can be detrimental to the health as previously reported.

As highlighted in Table 1, varieties of food samples were found to be contaminated with aflatoxin. The detection rate ranged from $16 \%$ up to $92 \%$ showing the ubiquitous presence of aflatoxin in the human food resources. Although the findings do not represent the whole scenario of aflatoxin contamination in Malaysia, such information shows the pervasiveness of human exposure to this food contaminant. In an instance, Reddy et al. (2011) detected aflatoxin in the foods normally consumed by Malaysian, where they are used and consumed on a daily basis. The presence of aflatoxin in the food chain is a serious matter but not knowing its impact to the health is a big problem and should be a public concern. Indeed in Malaysia, a recent survey reported low awareness and knowledge among the public on the problems associated with fungal and aflatoxin contamination in the diets (Mohd Redzwan et al., 2012a). Furthermore, the similar observations were also reported by several studies in African countries (Jolly et al., 2006, 2009; Ilesanmi and Ilesanmi, 2011). 


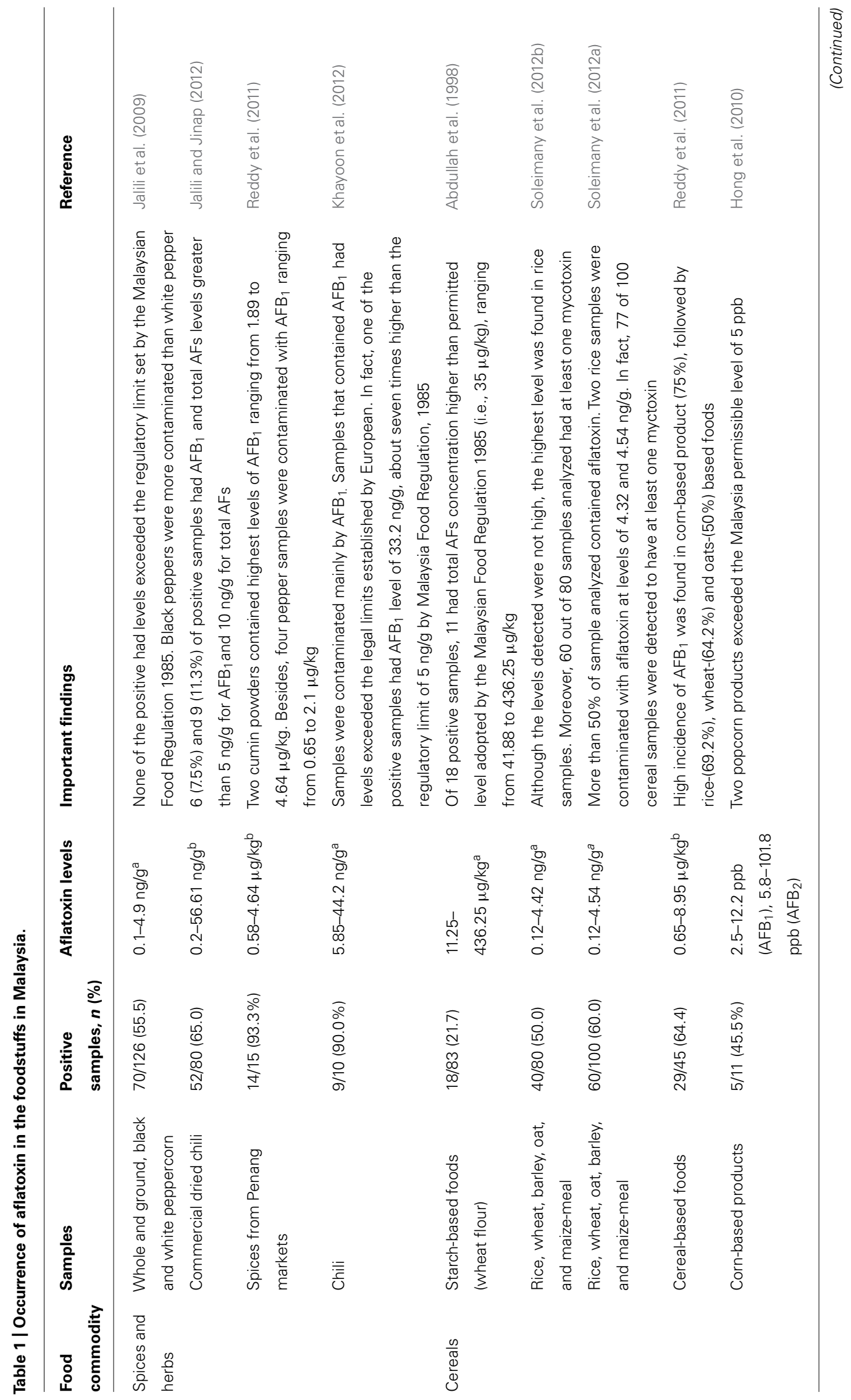




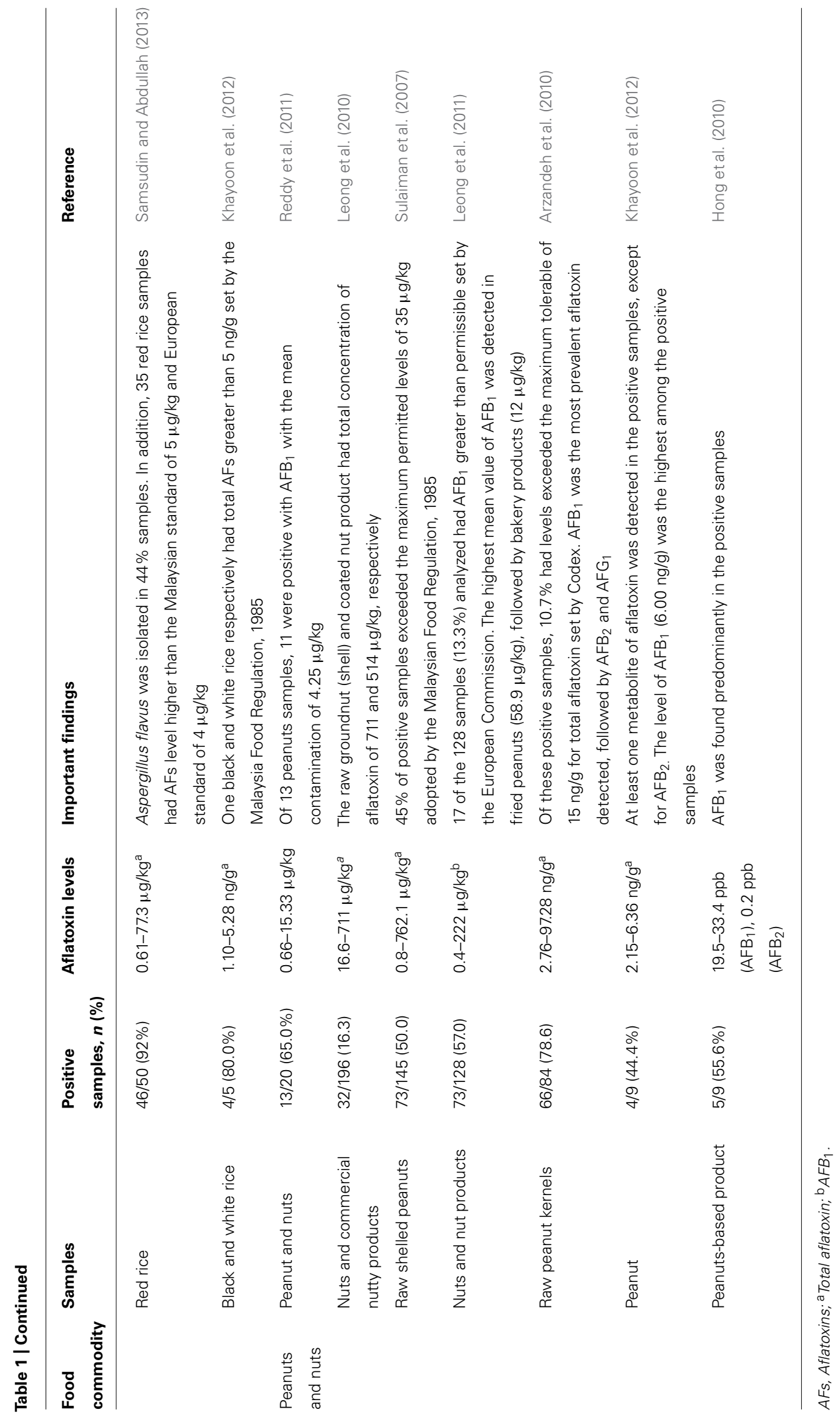


Exposure assessment by measuring aflatoxin levels in the food samples and extrapolating to estimate average intake at the population level is of low reliability (Kensler et al., 2011). The reason is such data cannot provide information on the individual's exposure as different individuals may have different exposure to aflatoxin. Nevertheless, the expansion of metabolomic study such as the use of aflatoxin biomarkers could provide the tools for molecular epidemiology to evaluate aflatoxin exposure among individuals within human population. Besides, measuring aflatoxin biomarkers could improve estimation of aflatoxin exposure (Liu and $\mathrm{Wu}, 2010)$. The aflatoxin biomarkes such as $\mathrm{AFB}_{1}$-DNA adduct, $\mathrm{AFB}_{1}$-lysine adduct, and urinary $\mathrm{AFM}_{1}$ have been documented in the literatures especially in African countries (Gong et al., 2002; Jolly et al., 2006; Shuaib et al., 2010) and China (Mykkänen et al., 2005; Xu et al., 2010), where aflatoxin contaminations are ubiquitous. These biomarkers are useful for epidemiologist and public health workers to make a better postulation on the extent and severity of aflatoxin exposure in a population. For example, the detection of $\mathrm{AFB}_{1}$-DNA adduct such as $\mathrm{AFB}_{1}-\mathrm{N}^{7}$-guanine in the urine samples could be an indicator of mutagenic effect of aflatoxin.

In Malaysia, exposure assessment by measuring aflatoxin biomarkers in human biological samples is still in its infancy. Nevertheless, several studies have reported the presence of these biomarkers among the Malaysia population. Indeed, it is believed that study by Zulhabri et al. (2009) is the first one in Malaysia that reported $\mathrm{AFB}_{1}$-albumin adduct in the HCC patients. Zulhabri et al. (2009) indicated that the HCC patients had significantly higher level of $\mathrm{AFB}_{1}$-albumin adduct compared to the healthy subjects. Aflatoxin can be an integral to the development of liver cancer (International Agency for Research on Cancer [IARC], 1993), thus the finding could provide an interesting insight on the synergistic effect of aflatoxin exposure. On the other hand, a recent study by Leong et al. (2012) found $\mathrm{AFB}_{1}$-lysine adduct in $97 \%$ of 170 subjects in Penang, with the levels ranging from 0.2 to $23.16 \mathrm{pg} / \mathrm{mg}$ albumin. The study also reported that Chinese and Indian respectively were 3.05 and 2.35 times more likely to have high $\mathrm{AFB}_{1}$-lysine adduct compared to the Malay (Leong et al., 2012). As a matter of fact, it was corroborated with a report from the Ministry of Health, Malaysia that showed high incidence of liver cancer among Chinese compared to other main ethnicities (Zainal Ariffin and Nor Saleha, 2011). Statistically in 2007, the report listed liver cancer as number 5 out of 10 most frequent cancers among male Chinese with the incidence rate of 5.9\% (Zainal Ariffin and Nor Saleha, 2011). Besides, the other aflatoxin biomarkers have also been investigated. A preliminary study involving 22 adult subjects found the presence urinary $\mathrm{AFM}_{1}$ ranging from 0.029 to $0.15 \mathrm{ng} / \mathrm{ml}$ (Sabran et al., 2012). Moreover, a significant and positive association was detected between urinary $\mathrm{AFM}_{1}$ with the consumption of milk and dairy products among 98 subjects with detectable level of $\mathrm{AFM}_{1}$ in Malaysia (Mohd Redzwan etal., 2012b). Since AFM 1 is a metabolite of $\mathrm{AFB}_{1}$, such findings indicated by Mohd Redzwan et al. (2012b) and Sabran et al. (2012) are useful to estimate human exposure to aflatoxin as a study has found good correlation between dietary intake of $\mathrm{AFB}_{1}$ and urinary excretion of metabolite $\mathrm{AFM}_{1}$ (Zhu et al., 1987).

Given that ingestion of aflatoxin can be linked to the development of liver cancer, a risk assessment can provide additional information on the extent of human exposure to this food contaminant. Risk assessment is the process of estimating the magnitude and the probability of a harmful effect to individuals or populations for certain agents or activities (Liu and $\mathrm{Wu}$, 2010). Several studies have reported Malaysian population could be exposed as high as $140 \mathrm{ng} / \mathrm{kg}$ body weight/day (Table 2). In one of the examples given in Table 2, Chin et al. (2012) indicated that Malaysian exposed to $\mathrm{AFB}_{1}$ ranging from 24.3 to $34 \mathrm{ng} / \mathrm{kg}$ body weight/day and such exposure could contribute to $12.4-17.3 \%$ of liver cancer in Malaysia. It was noteworthy as Liu and $\mathrm{Wu}$ (2010) described that more than 55 billion people worldwide facing uncontrolled exposure of aflatoxin and the burden of aflatoxin-induced liver cancer still remained unclear. Although it seems impossible to remove and eliminate aflatoxin completely from the food chain, these data are useful to develop plans to control and monitor aflatoxin in the foodstuffs. In fact, interventions could be done to prevent human exposure to aflatoxin and reduce the incidence of aflatoxin-related diseases in Malaysia.

Table 2 | Risk assessment of aflatoxin exposure in Malaysia.

\begin{tabular}{|c|c|c|c|}
\hline $\begin{array}{l}\text { Dietary AFB } 1 \text { exposure (ng/kg } \\
\text { body weight/day) }\end{array}$ & $\begin{array}{l}\text { Estimated liver cancer risk } \\
\text { (Cases/100, } 000 \text { population/year) }\end{array}$ & $\begin{array}{l}\text { Cancer incidence attributable to } \\
\text { dietary aflatoxin (\%) }\end{array}$ & Reference \\
\hline $24.37-34.00$ & $0.61-0.85$ & $12.4-17.3$ & Chin et al. (2012) \\
\hline $28.81-58.02^{a}$ & $0.72-1.45$ & $14.7-29.6$ & \\
\hline $0.36-8.89$ & $0.03-0.73$ & $0.61-14.9^{c}$ & Leong etal. (2011) \\
\hline 26.2 & $0.66^{b}$ & $13.5^{\mathrm{b}}$ & Sabran et al. (2012) \\
\hline $15-140$ & $4.5-42^{d}$ & $91-857^{c}$ & Liu and Wu (2010) \\
\hline 10.69 & $0.27^{\mathrm{b}}$ & $5.5^{b}$ & Arzandeh et al. (2010) \\
\hline
\end{tabular}

\footnotetext{
a Dietary aflatoxin exposure.

${ }^{b}$ The value was calculated based on formula given by Chin et al. (2012) - (Dietary exposure $\times 0.025$ cancers/100, 000 in Malaysia)

${ }^{\mathrm{C}}$ The value was computed from formula by Chin et al. (2012) - (Estimated liver cancer risk per 10,000 population/incidence rate of liver cancer in Malaysia of 4.9 per $100,000 \times 100 \%)$.

d Data obtained from estimated annual HCC per 100,000 population for HBsAG-positive.
} 


\section{FUTURE - MONITORING AND CONTROLLING THE OCCURRENCE OF AFLATOXIN AND INTERVENTION STRATEGIES}

It is a very important task to monitor and control the presence of aflatoxin in the human food resources as it involves many aspects. The legislation of law for instance by setting a certain limit can be considered as the "first defense" to prevent aflatoxin exposure to human. This rule was established following the massive outbreak of diseases associated with aflatoxin back in 1960s as mentioned earlier. Prior to that in Malaysia, aflatoxin was not considered to be a significant problem as it was not covered by the Sale of Food and Drug Ordinance 1952. In fact, the ruling on aflatoxinassociated cases was referred from countries such as in UK and USA (Hamid, 1997). However, around 1980s, Malaysia has promulgated stricter standards to prevent the "flow" of aflatoxin in the food chain by the implementation of Malaysia Food Regulation 1985, through the Food Act 1983. Initially, a maximum limit of $35 \mu \mathrm{g} / \mathrm{kg}$ for all mycological contaminants was implemented as reported by studies back in 1990s (Hamid, 1997; Abdullah etal., 1998; Ali et al., 1999). Later, it was revised and the new legislation limit was set to $5 \mu \mathrm{g} / \mathrm{kg}$ for all mycological contaminants including aflatoxin. Moreover, a limit of 15 and $0.5 \mu \mathrm{g} / \mathrm{kg}$ was set for groundnut for further processing and milk products respectively.

With the enforcement of law, it will be meaningless if no proper actions are taken by the public to remove the aflatoxincontaminated foodstuffs from the line of production. Although Malaysia has joined Codex Alimentarius since 1971 and strengthened the law on the occurrence of aflatoxin in the foodstuffs, it is still believed that some of the contaminated foods might "escape" during the surveillance process and persist in the food chain. A few studies explained that some contaminated foods may be perceived as safe and edible if there are no sign of defects and contaminations (Jolly et al., 2006; Mohd Redzwan et al., 2012b). Since the main route of human exposure to aflatoxin is through the diets, humans can be directly and/or indirectly exposed. Predicated upon that, interventions strategies have been carried out globally. Liu and Wu (2010) classified the strategies into three categories namely agricultural, dietary, and clinical. The agricultural interventions can be applied during pre- or post-harvest. This strategy is considered as the main primary intervention whereas dietary and clinical interventions are regarded as the secondary intervention (Liu and $\mathrm{Wu}$, 2010).

Since then, various research around the globe have come up with measures to limit human exposure to this food contaminant. The use of adsorbents such as activated carbon, hydrated sodium calcium alumino silicate, zeolite, bentonite, and certain clays are beneficial as they are proven to prevent aflatoxin absorption (Denli and Okan, 2006; Thieu and Pettersson, 2008; Gallo et al., 2010). Recently, the use of probiotic has been studied as one the potential adsorbents of aflatoxin in the gastrointetstinal tract. The in vitro and animal studies found the potential of certain probiotic lactic acid bacteria in reducing the bioavailability of aflatoxin (El-Nezami et al., 1998; Haskard et al., 2000; Lahtinen et al., 2004; Gratz et al., 2006; Hernandez-Mendoza et al., 2009; Nikbakht Nasrabadi et al., 2013). In fact, probiotics have many beneficial health effects (Oelschlaeger, 2010), thus its use to counteract the toxicity of alfatoxin could be further examined as one the preventive strategies.

\section{CONCLUSION}

Malaysia is a country that is shifting to become a fully developed nation by 2020 and agricultural sector is one of the driving forces for the economy. The occurrence of aflatoxin in the agricultural commodities can be a big loss to the economy and consequently affect the nation. Aflatoxin is dangerous and potent toxin as a number of expert groups have reviewed the health effect of aflatoxin (International Agency for Research on Cancer [IARC], 1993; Joint FAO/WHO Expert Committee on food additives [JECFA], 1998). In Malaysia, reports and publications on the level of aflatoxin in the foodstuffs are abundant. Nevertheless, from the scarce literatures of human exposure to aflatoxin, it is clear that more works need to be done on this very important matter. This is because the information is useful to estimate the magnitude of aflatoxin exposure in Malaysia. On the global scale, a worldwide networking with other nations is essential to gather data and information for harmonization in order to prevent this problem continuing to happen in the future.

\section{ACKNOWLEDGMENT}

Sabran Mohd-Redzwan would like to thank Ministry of Higher Education, Malaysia for providing scholarship for his postgraduate studies.

\section{REFERENCES}

Abdullah, N., Nawawi, N., and Othman, I. (1998). Survey of fungal counts and natural occurrence of aflatoxins in Malaysian starch-based food. Mycopathologia 143, 53-58. doi: 10.1023/A:1006945514876

Ali, N., Hashim, N. H., and Yoshizawa, T. (1999). Evaluation and application of a simple and rapid method for analysis of aflatoxins in commercial foods from Malaysia and the Phillipines. Food Addit. Contam. 16, 273-280. doi: 10.1080/026520399283939

Arzandeh, S., Selamat, J., and Lioe, H. (2010). Aflatoxin in raw peanut kernels marketed in Malaysia. J. Food Drug Anal. 18, 44-50.

Chin, C. K., Abdullah, A., and Sugita-Konishi, Y. (2012). Dietary intake of aflatoxins in the adults Malaysian population - an assessment of riks. Food Addit. Contam. Part B Surveill. 5, 286-294. doi: 10.1080/19393210.2012.713028

Denli, M., and Okan, F. (2006). Efficacy of different adsorbents in reducing the toxic effects of aflatoxin B1 in broiler diets. S. Afr. J. Anim. Sci. 36, 222-228.

El-Nezami, H., Kankaapaa, P., Salminen, S., and Ahokas, J. (1998). Ability of dairy strains of lactic acid bacteria to bind a common food cacrcinogen, aflatoxin B1. Food Chem. Toxicol. 36, 321-326. doi: 10.1016/S0278-6915(97)00160-9

Gallo, A., Masoero, F., Bertuzzi, T., Piva, G., and Pietri, A. (2010). Effect of the inclusion of adsorbents on aflatoxin B1 quantification in animal feedstuffs. Food Addit. Contam. 27, 54-63. doi: 10.1080/02652030903207219

Gong, Y. Y., Cardwell, K., Hounsa, A., Egal, S., Turner, P. C., Hall, A. J., et al. (2002). Dietary aflatoxin exposure and impaired growth in young children from Benin and Togo: cross sectional study. BMJ 325, 20-21. doi: 10.1136/bmj.325. 7354.20

Gratz, S., Taubel, M., Juvonen, M. T., Viluksela, M., Turner, P. C., Mykkanen, H., et al. (2006). Lactobacillus rhamnosus strain GG modulates intestinal absorption, fecal excretion and toxicity of aflatoxin B1 in rats. Appl. Environ. Microbiol. 72, 7398-7400. doi: 10.1128/AEM.01348-06

Groopman, J. D., Johnson, D., and Kensler, T. W. (2005). Aflatoxin and hepatitis B virus biomarkers: a paradigm for complex environmental exposures and cancer risk. Cancer Biomark. 1, 5-14.

Hamid, A. B. (1997). "Present status and future prospects of research on the groundnuts aflatoxin problem in Malaysia," in Aflatoxin Contamination Problems in Groundnut in Asia: Proceeding of the First Asia Working Group Meeting, eds V. K. 
Mehan and C. L. L. Gowda (Hyderabad: International Crops Research Institute for the Semi-Arid Tropics), 32-35.

Haskard, C., Binnion, C., and Ahokas, J. (2000). Factors affecting the sequestration of aflatoxin by Lactobacillus rhamnosus strain GG. Chem. Biol. Interact. 128, 39-49. doi: 10.1016/S0009-2797(00)00186-1

Hernandez-Mendoza, A., Guzman-de-Pena, D., and Garcia, H. S. (2009). Key role of techoic acids on aflatoxin B1 binding by probiotic bacteria. J. Appl. Microbiol. 107, 395-403. doi: 10.1111/j.1365-2672.2009.04217.x

Hong, L. S., Mohd Yusof, N. I., and Ling, H. M. (2010). Determination of Aflatoxin B1 and B2 in peanuts and corn based products. Sains Malays. 39, 731-735.

"IARC, International Agency for Research on Cancer." (1993). "Aflatoxin," in Some Naturally Occurring Substances: Food Items and Constituents, Heterocyclic Aromatic Amines and Mycotoxins. IARC Monographs on the Evaluation of Carcinogenic Risks to Humans, Vol. 56 (Lyon: IARC), 245-395.

Ilesanmi, F. F., and Ilesanmi, O. S. (2011). Knowledge of aflatoxin contamination in groundnut and risk of its ingestion among health workers in Ibadan, Nigeria. Asian Pac. J. Trop. Biomed. 1, 493-495. doi: 10.1016/S2221-1691(11) 60108-1

Jalili, M., and Jinap, S. (2012). Natural occurrence of aflatoxins and ochratoxin A in commercial dried chili. Food Control 24, 160-164. doi 10.1016/j.foodcont.2011.09.020

Jalili, M., Jinap, S., and Adzahan, N. (2009). Survey of aflatoxin in retail samples of whole and ground black and white peppercorns. Food Addit. Contam. Part B Surveill. 2, 178-182. doi: 10.1080/19440040903384190

JECFA, Joint FAO/WHO Expert Committee on food additives. (1998). "Safety evaluation of certain food additives and contaminants in foods: aflatoxin. WHO Food Additives Series 40," in 49th meeting of the Joint FAO/WHO Expert Committee on Food Additives, (Geneva: World Health Organization), 359-469.

Jolly, C. M., Bayard, B., Awuah, R. T., Fialor, S. C., and Williams, J. T. (2009) Examining the structure of awareness and perceptions of groundnuts aflatoxin among Ghanaian health and agricultural professionals and its influence on their actions. J. Socioecon. 38, 280-287. doi: 10.1016/j.socec.2008.05.013

Jolly, P., Jiang, Y., Ellis, W., Awuah, R., Nnedu, O., Phillips, T., et al. (2006). Determinants of aflatoxin levels in Ghanaians: sociodemographic factors, knowledge of aflatoxin and food handling and consumption practices. Int. J. Hyg. Environ Health 209, 345-358. doi: 10.1016/j.ijheh.2006.02.002

Kensler, T. W., Roebuck, B. D., Wogan, G. N., and Groopman, J. D. (2011). Aflatoxin: a 50-year odyssey of mechanistic and translational toxicology. Toxicol. Sci. 120 S28-S48. doi: 10.1093/toxsci/kfq283

Khayoon, W. S., Saad, B., Lee, T. P., and Salleh, B. (2012). High performance liquid chromatographic determination of aflatoxins in chili, peanut and rice using silica based monolithic column. Food Chem. 133, 489-496. doi 10.1016/j.foodchem.2012.01.010

Lahtinen, S. J., Haskard, C. A., Ouwehand, A. C., Salminen, S. J., and Ahokas, J. T. (2004). Binding of aflatoxin B1 to cell wall components of Lactobacillus rhamnosus strain GG. Food Addit. Contam. 21, 158-164. doi: 10.1080/02652030310001639521

Leong, Y. H., Ismail, N., Latiff, A. A., and Ahmad, R. (2010). Aflatoxin occurrence in nuts and commercial nutty products in Malaysia. Food Control 21, 334-338. doi: 10.1016/j.foodcont.2009.06.002

Leong, Y. H., Rosma, A., Latiff, A. A., and Ahmad, N. I. (2011). Exposure assessment and risk characterization of aflatoxin B1 in Malaysia. Mycotoxin Res. 27, 207-214 doi: 10.1007/s12550-011-0097-4

Leong, Y. H., Rosma, A., Latiff, A. A., and Nurul Izzah, A. (2012). Associations of serum aflatoxin B1-lysine adduct level with socio-demographic factors and aflatoxin intake from nuts and related nut products in Malaysia. Int. J. Hyg. Environ. Health 215, 368-372. doi: 10.1016/j.ijheh.2011.12.005

Lim, H. K., and Yeap, G. S. (1966). The occurrence of aflatoxin in Malayan imported oil cakes and groundnut kernels. Malayan Agric. J. 45, 232-244.

Liu, Y., and Wu, F. (2010). Global burden of aflatoxin-induced hepatocellular carcinoma: a risk assessment. Environ. Health Perspect. 118, 818-824. doi 10.1289/ehp.0901388

Lye, M. S., Ghazali, A. A., Mohan, J., Alwin, N., and Nair, R. C. (1995). An outbreak of acute hepatic encephalopathy due to severe aflatoxicosis in Malaysia. Am. J. Trop. Med. Hyg. 53, 68-72.

MOH, Ministry of Health. (2006). Food Consumption Statistic of Malaysia 2002/2003 for Adult Population Aged 18-59 Years. Vol. 1, Putrajaya: Ministry of Health, Malaysia.
Mohd Redzwan, S., Rosita, J., Mohd Sokhini, A. M., and Nurul Aqilah, A. R. (2012a) Socio-demographic and socio-economic determinants of adults knowledge on fungal and aflatoxin contamination in the diets. Asian Pac. J. Trop. Biomed. 2, S1835-S1841. doi: 10.1016/S2221-1691(12)60504-8

Mohd Redzwan, S., Rosita, J., Mohd Sokhini, A. M., and Nurul Aqilah, A. R. (2012b). Association between aflatoxin M1 excreted in human urine samples with the consumption of milks and dairy products. Bull. Environ. Contam. Toxicol. 89, 1115-1119. doi: 10.1007/s00128-012-0853-y

Mykkänen, H., Zhu, H., Salminen, E., Juvonen, R. O., Ling, W., Ma, J., et al (2005). Fecal and urinary excretion of aflatoxin B1 metabolites (AFQ1, AFM1, and AFB-N7-guanine) in young Chinese males. Int. J. Cancer 115, 879-884. doi: 10.1002/ijc. 20951

Nikbakht Nasrabadi, E., Jamaluddin, R., Abdul Mutalib, M. S., Khaza'ai, H., Khalesi, S., and Mohd Redzwan, S. (2013). Reduction of aflatoxin level in aflatoxin-induced rats by the activity of probiotic Lactobacillus casei strain Shirota. J. Appl. Microbiol. 114, 1507-1515. doi: 10.1111/jam. 12148

Oelschlaeger, T. A. (2010). Mechanisms of probiotic actions - a review. Int. J. Med. Microbiol. 300, 57-62. doi: 10.1016/j.ijmm.2009.08.005

Paterson, R. R. M., and Lima, N. (2010). “Toxicology of mycotoxins," in Molecular, Clinical and Environmental Toxicology. Volume 2: Clinical Toxicology, ed. A. Luch (Zürich: Birkhauser Verlag), 31-63.

Polychronaki, N., Wild, C. P., Mykkänen, H., Amra, H., Abdel-Wahhab, M., Sylla, A., Diallo, M., etal. (2008). Urinary biomarkers of aflatoxin exposure in young children from Egypt and Guinea. Food Chem. Toxicol. 46, 519-526. doi: 10.1016/j.fct.2007.08.034

Reddy, K. R. N., Farhana, N. I., and Salleh, B. (2011). Occurrence of Aspergillus spp. and aflatoxin B1 in Malaysian foods used for human consumption. J. Food Sci. 76, T99-T104. doi: 10.1111/j.1750-3841.2011.02133.x

Sabran, M. R., Jamaluddin, R., and Abdul Mutalib, M. S. (2012). Screening of aflatoxin M1, a metabolite of aflatoxin B1 in human urine samples in Malaysia: a preliminary study. Food Control 28, 55-58. doi: 10.1016/j.foodcont.2012. 04.048

Samsudin, N. I. P., and Abdullah, N. (2013). A preliminary survey on the occurrence of mycotoxigenic fungi and mycotoxins contaminating red rice at consumer level in Selangor, Malaysia. Mycotoxin Res. 29, 89-96. doi: 10.1007/s12550-0120154-7

Shuaib, F. M., Jolly, P. E., Ehiri, J. E., Yatich, N., Jiang, Y., Funkhouser, E., et al. (2010). Association between birth outcomes and aflatoxin B1 biomarker blood levels in pregnant women in Kumasi, Ghana. Trop. Med. Int. Health 15, 160-167. doi: 10.1111/j.1365-3156.2009.02435.x

Soleimany, F., Jinap, S., and Abas, F. (2012a). Determination of mycotoxins in cereals by liquid chromatography tandem mass spectrometry. Food Chem. 130, 1055-1060. doi: 10.1016/j.foodchem.2011.07.131

Soleimany, F., Jinap, S., Faridah, A., and Khatib, A. (2012b). A UPLC-MS/MS for simultaneous determination of aflatoxins, ochatoxin A, zearenone, DON, dumonisims, T-2 toxin and HT-2 toxin, in cereals. Food Control 25, 647-653. doi: 10.1016/j.foodcont.2011.11.012

Sulaiman, M. R., Yee, C. F., Hamid, A., and Yatim, A. M. (2007). The occurrence of aflatoxins in raw shelled peanut samples from three districts of Perak, Malaysia. Electron. J. Environ. Agric. Food Chem. 6, 2045-2052.

Thieu, N. Q., and Pettersson, H. (2008). In vitro evaluation of the capacity of zeolite and bentonite to adsorb aflatoxin B1 in simulated gastrointestinal fluids. Mycotoxin Res. 24, 124-129. doi: 10.1007/BF03032338

Wang, J. S., Shen, X., He, X., Zhu, Y. R., Zhang, B. C., Wang, J. B., et al. (1999). Protective alteration in Phase 1 and 2 metabolism of aflatoxin B1 by oltipraz in residents of Qidong, People's Republic of China. J. Natl. Cancer Inst. 91, 347-354. doi: 10.1093/jnci/91.4.347

Xu, L., Qian, C., Tang, L., Su, J., and Wang, J.-S. (2010). Genetic variations of hepatitis B virus and serum aflatoxin-lysine adduct on high risk of hepatocellular carcinoma in Southern Guangxi, China. J. Hepatol. 53, 671-676. doi: 10.1016/j.jhep.2010.04.032

Zainal Ariffin, O., and Nor Saleha, I. T. (2011). National Cancer Registy Report 2007. Malaysia Cancer Statistics - Data and Figure. Putrajaya: National Cancer Registry, Ministry of Health Malaysia.

Zhu, J. Q., Zhang, L. S., Hu, X., Xiao, Y., Chen, J. S., Xu, Y. C., et al. (1987). Correlation of dietary aflatoxin B1 levels with excretion of aflatoxin M1 in human urine. Cancer Res. 47, 1848-1852. 
Zulhabri, O., Jamal, R., Isa., M. R., Harjit, S., and Wang Ngah, W. Z. (2009). Hotspot Ser-249 TP53 mutations, aflatoxin B1-adducts and hepatitis $\mathrm{B}$ infection in human hepatocellular carcinoma from Malaysia. Med. J. Mal. 64 (Suppl B), 88.

Conflict of Interest Statement: The authors declare that the research was conducted in the absence of any commercial or financial relationships that could be construed as a potential conflict of interest.

Received: 27 August 2013; paper pending published: 09 September 2013; accepted: 22 October 2013; published online: 13 November 2013.
Citation: Mohd-Redzwan S., Jamaluddin R., Abd.-Mutalib MS, Ahmad Z (2013) A mini review on aflatoxin exposure in Malaysia: past, present, and future. Front. Microbiol. 4:334. doi: 10.3389/fmicb.2013.00334

This article was submitted to Food Microbiology, a section of the journal Frontiers in Microbiology.

Copyright (C) 2013 Mohd-Redzwan, Jamaluddin, Abd.-Mutalib and Ahmad. This is an open-access article distributed under the terms of the Creative Commons Attribution License (CC BY). The use, distribution or reproduction in other forums is permitted, provided the original author(s) or licensor are credited and that the original publication in this journal is cited, in accordance with accepted academic practice. No use, distribution or reproduction is permitted which does not comply with these terms. 